spectively on data recorded in a prospective mode in the first instance, before the suspected relationship between the morbidity and the drug had been identified at all. The rest of the patients of the recording practices who are not suffering from the morbidity act as a source for suitable controls. The total morbidity for all patients is available as a standardised baseline. This method for retrospective control studies avoids the need for costly exercises in linking records with prescribing data from other sources.

The Birmingham Research Unit of the Royal College of General Practitioners is at present organising a programme for testing certain suspected morbid associations with commonly used drugs, but the system could be available for wider use as a component in any integrated programme for hypothesis testing of this kind.

D L CRombie Director, General Practice Research Unit,
Royal College of General Practitioner

Birmingham

1 Research Unit, fournal of the College of General Practitioners, 1971, 21, 609

- Crombie, D L, Fournal of the Royal College of General Practitioners, 1975, 25, 337.

Research Unit, fournal of the College of General

Practitioners, 1959, 2,140.

Research Unit, fournal of the College of General
Practitioners, 1967, 13, 267.

2,355 .

\section{Cutting the drug bill}

SIR,-We have recently completed a fourweek project which may be of interest to our general practitioner colleagues. With the assistance of a local pharmacist we selected a group of nine commonly prescribed expensive drugs and on every FP10 issued we used only their generic names. The drugs chosen, together with their most familiar proprietary names were as follows: diazepam (Valium), frusemide (Lasix), phenylbutazone (Butazolidin), amitriptyline (Tryptizol), indomethacin (Indocid), ampicillin (Penbritin), imipramine (Tofranil), methyldopa (Aldomet), and nitrazepam (Mogadon). The list did not include other commonly prescribed products such as penicillin, oxytetracycline, antacids, etc because it has been our usual practice to use generic names in these cases. The patients were informed that we were now using the "chemical" names in their prescriptions "similar to those used by the hospital." Some patients were initially confused but soon readily accepted the new name. In no case did we have any objection on clinical or therapeutic grounds.

At the end of the four-week period we costed the alternatives and found we had saved approximately $£ 120$. This would mean a saving of approximately $£ 1500$ per year in our 4500 two-man practice. If this were repeated over the country as a whole it would save in the region of $f 15 \mathrm{~m}$ to the NHS.

In times of stringent financial economy when the hospital and community services throughout the country are being asked to skimp and save we feel that it behoves our GP colleagues to scrutinise their prescribing habits. We find that this scheme had no detrimental effect on direct patient care and was a rewarding exercise in self-audit.

We would also like to see the Department of Health and Social Security take a far more active advisory role in promoting that excellent publication the British National Formulary.
We are besieged by drug-firm representatives competing for our custom. We are "bribed" with luncheons, dinners, gifts, samples, etc and it is not surprising that this continual barrage of proprietary drug advertisement produces a less discriminatory approach to prescribing. We feel that the Department could arrange for GPs to be visited regularly - say, every six months or so-by wellinformed, well-briefed doctors and pharmacists, who have a wealth of experience. Many retired professional colleagues would no doubt be delighted to accept part-time work on such a worthwhile project. The savings effected by this scheme would far exceed the cost.

Monte Lubel A K SINHA

Westcliff-on-Sea, Essex

\section{Staffing in the medical laboratory service}

SIR,-In responding to your leading article (2 April, p 866) entitled "The pathologis must control the laboratory" we are fully in agreement with the conclusion expressed in the title for the very excellent reasons which you give. The success of clinical pathology as we have known it (some of us for 30 years or more) has been due in large measure to the harmonious symbiotic relationship between the medical and technological staff working in it, in which each side knew the other's skills and responsibilities and respected them. This situation must continue if the peculiar art of the laboratory-based doctor is to be available to the patients of his area.

It is our opinion that certain aspects of the policy advocated by the Institute of Medical Laboratory Sciences in their evidence to the Royal Commission bring out very clearly a division between us which is beginning to appear and which carries with it a very rea danger of disrupting the necessary happy relationship we have enjoyed until now. It seems to us that war may develop in the clouds of institutes, colleges, and associations above our heads, but resulting in destruction at the laboratory level of harmony which is essential for the proper maintenance of a patient service. If a technologist-versus-pathologist situation aided by a scientist wedge between the two is allowed to develop the good will amongs us all which sustains the service that we try to give may well suffer considerable damage. If we retain and develop a proper appreciation of each other's contribution there is no need for this to happen.

\section{JOHN M TALBOT \\ FREY R ELLIS \\ B W MEADE}

Department of Patholog

Kingston and Richmond Area Health Authority, Kingston upon Thames, Surrey

SIR,-We would like to support the comments made by Professor L G Whitby and others (26 March, p 833) about the role of graduate scientists in the laboratory services. We too are unable to accept the Institute of Medical Laboratory Sciences policy statement ${ }^{1}$ and their subsequent document presenting evidence to the Royal Commission ${ }^{2}$ and are very concerned about the apparent total lack of insight by the IMLS into the contributions made by graduate scientists.

The role that should be made by graduate scientists in the laboratory services is complementary to that of technical staff and we wholly endorse Professor Whitby's comments on this matter. If functions such as research and development, clinical liaison, and interpretation of data are not fulfilled laboratories will become little more than factories, perhaps efficient ones, but performing useless tests. As laboratory services inevitably become more specialised it is the responsibility of the laboratory to educate the users of the service so that the best, in terms of service to the patient, can be obtained from the apparently diminishing resources available. Many of those who advocate merging the role of the graduate scientist with that of the technician appear to be making a dangerous assumption that the present role of the graduate can be readily undertaken by the clinician, and regrettably this view is also shared by a minority of the medical profession. Consideration of the fact that many science graduates spend five or six years learning at university, quite analogous to the training of the medical graduate, and take higher qualifications such as the MCB or MRCPath should soon dispel this idea. We believe that the team approach to providing a medical laboratory service, with medical staff, graduate scientists, and technicians each providing part of the total service, is the only way of ensuring a balanced acceptable service.

Finally, we wish to make it clear that we are not opposed to, and indeed would support an integrated staffing structure so that all individuals can progress along a path appropriate to their qualifications, training, and experience, provided that the role of the graduate is recognised at all levels. If graduate scientists become unable to fulfill their proper role and maintain their status then they will cease to enter the NHS and as a result we predict that the laboratory service will succumb to the grey tide of mediocrity sweeping all sectors of our society, producing yet another retrograde step in patient care.

ANNE GREEN

IAN D MARSH

Mavis S Greaves

JOHN WATKINS

M BENTON

B R BEVAN

Children's Hospital

Hallamshire Medical School,

Nospital, Royal Infirmary,

and Jessop Hospital for Women,

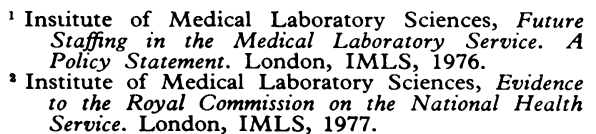

to the Royal Commission on the National Health

\section{Experiments with computers}

SIR,-We write as two individuals directly concerned with the evaluation of computer projects within the Department of Health and Social Security's experimental programme. We would like to point out that in your summary (12 February, p 404) of the Public Accounts Committee report ${ }^{1}$ you have reproduced some of the factual errors and misleading statements. For example, the London Hospital has not dropped any stages of its bed-state systemphase I has been operating across the whole hospital since April 1973 and phase II since August 1975. The statement that Stoke has spent $£ 1.7 \mathrm{~m}$ saving five minutes per patient is totally misleading. The Stoke project has of course achieved far more than savings in 